\title{
Platelet count squared/spleen diameter-aspartate aminotransferase ratio: non-invasive method to predict esophageal varices
}

\author{
Ângelo Zambam de MATTOS ${ }^{1,2,3}$, Larissa Faraco DAROS $^{2}$ and Angelo Alves de MATTOS ${ }^{2,3}$
}

Received 20/12/2016

Accepted 7/2/2017

\begin{abstract}
Background - Variceal bleeding has a high mortality among cirrhotics, and screening with endoscopy is indicated at the diagnosis of cirrhosis. Screening with endoscopy implies discomfort, risks and considerable costs. Objective - To evaluate platelet count squared/spleen diameter-aspartate aminotransferase ratio (PS/SA), as a non-invasive predictor of esophageal varices in cirrhotics. Methods - This cross-sectional study evaluated cirrhotics for PS/SA and presence of esophageal varices. Outpatient records of cirrhotic patients were reviewed for the abovementioned data. Sensitivity, specificity, negative and positive predictive values of PS/SA were calculated. After the univariate analysis, variables with $P<0.10$ were submitted to a logistic regression. Results - The study included 164 cirrhotics, $59.70 \%$ male, with a mean age of 56.7 years. Hepatitis C was the most frequent cause of cirrhosis, being present in 90 patients. Patients were classified as Child-Pugh A in $52.44 \%$ and as Child-Pugh B or C in $47.56 \%$. Esophageal varices were present in $72.56 \%$ of the patients at endoscopy. PS/SA, with a cutoff of $3 \times 10^{8}$, had a sensitivity of $95.80 \%$ (confidence interval of $95 \%$ $95 \% \mathrm{CI}=0.92-0.99)$, a specificity of $22.70 \%(95 \% \mathrm{CI}=0.10-0.35)$, a positive predictive value of $77.20 \%(95 \% \mathrm{CI}=0.70-0.84)$ and a negative predictive value of $66.70 \%(95 \% \mathrm{CI}=0.42-0.91)$. In the logistic regression, only platelet count and Child-Pugh score were associated to esophageal varices $(P<0.05)$. Conclusion - PS/SA has an excellent sensitivity to predict esophageal varices, allowing almost one fourth of patients without esophageal varices to spare endoscopy. Nevertheless, PS/SA is not independently associated to esophageal varices.
\end{abstract}

HEADINGS - Liver cirrhosis. Esophageal and gastric varices. Portal hypertension. Gastrointestinal endoscopy. Platelet count.

\section{INTRODUCTION}

Cirrhotic patients have esophageal varices (EV) in up to $60 \%$ of cases, and variceal bleeding is associated to a mortality rate of $15 \%-20 \%{ }^{(2)}$. This is why the American Association for the Study of Liver Disease $^{(7)}$ and the Baveno Consensus ${ }^{(5)}$ advise the screening of EV in cirrhotics. Actually, according to the Baveno Consensus ${ }^{(5)}$ the only patients who might safely avoid a screening endoscopy would be those with compensated advanced chronic liver disease and both a liver stiffness measurement under $20 \mathrm{kPa}$ and a platelet count over $150,000 / \mathrm{mm}^{3}$, which was validated in a recent study ${ }^{(1)}$. Nevertheless, important societies do not support using any noninvasive test instead of endoscopy for variceal screening ${ }^{(6)}$.

Screening with endoscopy implies discomfort, risks and considerable costs, which is even more important when one considers public health systems. In an attempt to reduce distress for patients and costs, many non-invasive methods to screen for EV are being studied. When we evaluated two of these methods, namely, platelet count/spleen diameter ratio $(\mathrm{PC} / \mathrm{SD})^{(8)}$ and aspartate aminotransferase-to-platelet ratio index (APRI) ${ }^{(13)}$, despite being associated to the presence of $\mathrm{EV}$ in the univariate analysis, none of them was independently related to it. Actually, the variable associated to EV in the multivariate analysis of both studies was platelet count ${ }^{(8,13)}$.

Therefore, considering the importance of platelet count in pre- dicting EV, we have tried to develop a model which would increase the value attributed to platelet count in predicting EV, as well as control it by a portal hypertension parameter, spleen diameter ${ }^{(2)}$, and by a fibrosis parameter, APRI ${ }^{(10)}$. This study analyzes the ability of platelet count squared/spleen diameter-aspartate aminotransferase ratio (PS/SA) in predicting the existence of $\mathrm{EV}$ in a population of cirrhotic patients.

\section{METHODS}

Records of patients from the outpatient clinic of cirrhosis of a general hospital in Southern Brazil were reviewed for this crosssectional study. Records should inform platelet count, spleen diameter, aspartate aminotransferase (AST) and endoscopy 6 months apart from each other at most. Endoscopists were not aware of $\mathrm{PS} / \mathrm{SA}$ results. EV were not classified in size for the purpose of this study because even small varices are likely to bleed if presenting with red marks or in Child-Pugh class $\mathrm{C}$ patients, situations in which prophylaxis is already indicated ${ }^{(5,7)}$. Spleen diameter was determined by ultrasonography, which was performed in all patients by the same group of radiologists.

PS/SA was calculated as follows: [platelet $\operatorname{count}^{2}\left(/ \mathrm{mm}^{3}\right) /$ spleen diameter (mm)] x AST (times above upper limit of normal). Data were calculated in order to verify sensitivity, specificity, negative

Declared conflict of interest of all authors: none

Disclosure of funding: no funding received

Research performed at: Federal University of Health Sciences of Porto Alegre and Irmandade Santa Casa de Misericórdia de Porto Alegre, Porto Alegre, Brazil.

${ }^{1}$ Pontifícia Universidade Católica do Rio Grande do Sul, Porto Alegre, RS, Brasil; ${ }^{2}$ Irmandade Santa Casa de Misericórdia de Porto Alegre, Porto Alegre, RS, Brasil; ${ }^{3}$ Universidade Federal de

Ciências da Saúde de Porto Alegre, Porto Alegre, RS, Brasil.

Correspondence: Ângelo Zambam de Mattos. Rua Professor Annes Dias, 154, sala 1103 - CEP: 90020-090 - Porto Alegre, RS, Brasil. E-mail: angmattos@hotmail.com 
and positive predictive values of the index, with a confidence interval of $95 \%(95 \% \mathrm{CI})$ and with a $P$-value of $5 \%$. ANOVA test was used to compare categorical and continuous variables, except if variances were not homogeneous, when Kruskal-Wallis test was used. Mantel-Haenszel's Chi-Square test was used for comparisons between categorical variables, except if values were less than 5 , when Fischer's exact test was preferred.

Platelet count, spleen diameter, PC/SD, APRI, AST/ALT ratio, Child-Pugh score and Model for End Stage Liver Disease (MELD) were included, along with PS/SA, in the univariate analysis. After the univariate analysis, variables with $P<0.10$ were submitted to a logistic regression. Epi Info ${ }^{\mathrm{TM}}$ 3.4.1 was used for the statistical analysis.

It was calculated that at least 139 patients were needed to produce results with a $95 \%$ level of confidence and a $10 \%$ length for the confidence intervals. This study was approved by the institutional Ethics Committee (reference number 1624.07), according to the Declaration of Helsinki of 1975. The institutional Ethics Committee considered that informed consent was not necessary for the present study.

\section{RESULTS}

One hundred and sixty four patients were consecutively included in the study, from which 98 were men $(59.76 \%)$. The mean age of the patients was 56.7 years. Hepatitis $C$ was present in 90 patients, and alcohol abuse, in 63 (some of the patients had both risk factors for liver disease). Patients were classified as Child-Pugh A in 86 cases $(52.44 \%)$ and as Child-Pugh B or C in 78 cases $(47.56 \%)$. EV were diagnosed by endoscopy in 119 patients $(72.56 \%)$. Other baseline characteristics of patients are shown in Table 1.

TABLE 1. Baseline characteristics of patients

\begin{tabular}{lc}
\hline Characteristics & Mean Values/Percentages \\
\hline Ascites & $8.59 \%$ \\
Hepatic encephalopathy & $3.07 \%$ \\
Total Bilirubin (mg/dL) & 1.66 \\
International Normalized Ratio & 1.31 \\
Albumin (g/dL) & 3.75 \\
Creatinine (mg/dL) & 1.02 \\
Alanine Aminotransferase (units/L) & 57.37 \\
Aspartate Aminotransferase (units/L) & 73.44 \\
Platelets (/mm ${ }^{3}$ ) & $96,834.36$ \\
Spleen Diameter (mm) & 146.14 \\
Model for End-Stage Liver Disease & 11.62 \\
\hline
\end{tabular}

One hundred and fifty three patients had complete data in order for the calculation of PS/SA. Among these patients, 114 had EV (74.51\%). The mean value of the index for patients without $\mathrm{EV}$ was 256,621,745.22 (standard deviation-SD=353,210,019.27), while, for patients with $\mathrm{EV}$, it was 77,743,669.49 (SD=189,389,006.13). When the index, at a cutoff of $2 \times 10^{7}$, was used in order to predict the existence of EV (i.e. patients with an index greater than $2 \times 107$ were predicted not to have $\mathrm{EV}$, while patients with an index equal or inferior to $2 \times 107$ were predicted to have EV), it had a sensitivity of $50.80 \%(95 \% \mathrm{CI}=0.42-0.60)$, a specificity of $65.90 \%(95 \% \mathrm{CI}=0.52-$ $0.80)$, a positive predictive value of $80.30 \%(95 \% \mathrm{CI}=0.71-0.89)$ and a negative predictive value of $33.00 \%(95 \% \mathrm{CI}=0.23-0.43)$. For a cutoff of $2 \times 10^{8}$, the index had a sensitivity of $90.80 \%$
$(95 \% \mathrm{CI}=0.86-0.96)$, a specificity of $31.80 \%(95 \% \mathrm{CI}=0.18-0.46)$, a positive predictive value of $78.40 \%(95 \% \mathrm{CI}=0.71-0.85)$ and a negative predictive value of $56.00 \%(95 \% \mathrm{CI}=0.36-0.76)$. For a cutoff of $3 \times 10^{8}$, it had a sensitivity of $95.80 \%(95 \% \mathrm{CI}=0.92-0.99)$, a specificity of $22.70 \%(95 \% \mathrm{CI}=0.10-0.35)$, a positive predictive value of $77.20 \%(95 \% \mathrm{CI}=0.70-0.84)$ and a negative predictive value of $66.70 \%(95 \% \mathrm{CI}=0.42-0.91)$. Near one fourth of patients without EV had a PS/SA greater than $3 \times 10^{8}$.

In the univariate analysis, PS/SA $(P<0.001)$, APRI $(P<0.001)$, platelet count $(P=0.001)$, spleen diameter $(P=0.015), \mathrm{PC} / \mathrm{SD}$ $(P<0.001)$, MELD score $(P=0.017)$ and Child-Pugh classification $(P=0.015)$ were associated to the presence of EV. The only studied variable not associated to EV was the AST/ALT ratio $(P=0.512)$. When the logistic regression was performed, though, only platelet count and Child-Pugh classification were independently associated to the presence of $\mathrm{EV}(P<0.050)$.

\section{DISCUSSION}

Defining cirrhotics at a greater risk for EV in a non-invasive manner is essential in order to reduce costs, discomfort and risks related to endoscopy. Endoscopy is an invasive and expensive procedure, which could be unnecessary in part of the patients diagnosed with cirrhosis. For a non-invasive test to be considered useful in the studied context, it should have a great sensitivity, since misdiagnosing cirrhotic patients as not having EV is a major risk, and it should be of low cost.

$\mathrm{PC} / \mathrm{SD}$, for instance, is a very low cost alternative, because it uses parameters which are part of every cirrhotic workup. Nevertheless, the systematic reviews published on this subject reached contradictory conclusions $^{(3,12)}$. More recently, elastography ${ }^{(4,11)}$ has been studied for the prediction of EV. Results, though not ideal, could be considered acceptable, but the high costs associated to elastography and its low availability do not allow it to be a good substitute for endoscopy at the moment ${ }^{(9)}$. The same could be said about the prediction of varices needing prophylaxis by a liver stiffness measurement under $20 \mathrm{kPa}$ and a platelet count over $150,000 / \mathrm{mm}^{3}$, which was suggested by the Baveno Consensus ${ }^{(5)}$ and recently validated ${ }^{(1)}$.

PS/SA uses three easily obtained parameters, which are part of the routine workup of cirrhotics and, thus, would not increase costs. Besides, the index presented a very good sensitivity, especially at the cutoff of $3 \times 10^{8}$, which would allow almost $25 \%$ of patients without EV to avoid endoscopy.

Sensitivity is the most important characteristic of a screening test. Comparing the sensitivity of PS/SA to that of other promising non-invasive methods for prediction of $\mathrm{EV}$, namely PC/SD and transient elastography, the index that we are now presenting performs well. Considering the results of 2 meta-analyses on $\mathrm{PCl}$ SD, the sensitivity of the method varies between $89 \%$ and $92 \% 0^{(3,12)}$, while we have shown sensitivities as high as $95.80 \%$ for PS/SA. Regarding elastography, different articles described a wide range of sensitivity values, varying from $67.00 \% 0^{(11)}$ to $96.20 \% \%^{(4)}$. Compared to the sensitivity of elastography, the sensitivity of PS/SA is better or, at least, similar. Again, one must take into consideration that elastography implies high costs, especially in developing countries, while PS/SA does not. Nevertheless, despite the good sensitivity of the method, PS/SA was not independently associated to EV in the multivariate analysis, which might be explained by the presence of confounding factors. 


\section{CONCLUSION}

In conclusion, though PS/SA is not independently associated to EV, it has an excellent sensitivity, better than most of other noninvasive methods for the prediction of EV. Since its use could allow almost one fourth of patients without EV to spare endoscopy, therefore saving costs, we believe this index should be further evaluated.

Study approved by the Ethics Committee of Santa Casa Hospital, according to the Declaration of Helsinki of 1975 (reference number 1624.07). The institutional Ethics Committee considered that informed consent was not necessary for the present study.

\section{Authors' contributions}

Mattos AZ: study concept and design; acquisition of data; analysis and interpretation of data; drafting of the manuscript; approval of the final version of the manuscript. Mattos AA: analysis and interpretation of data; critical revision of the manuscript for important intellectual content; approval of the final version of the manuscript. Daros LF: acquisition of data; critical revision of the manuscript for important intellectual content; approval of the final version of the manuscript.

Mattos AZ, Daros LF, Mattos AA. Razão da contagem de plaquetas ao quadrado/diâmetro do baço-aspartato aminotransferase: avaliação de um novo método não-invasivo para a predição de varizes esofágicas. Arq Gastroenterol. 2017;54(3):222-4.

RESUMO - Contexto - A hemorragia varicosa tem elevada mortalidade entre cirróticos, e o rastreamento endoscópico de varizes está indicado no momento do diagnóstico da cirrose. O rastreamento endoscópico implica desconforto, riscos e custos consideráveis. Objetivo - Avaliar a razão da contagem de plaquetas ao quadrado/diâmetro do baço-aspartato aminotransferase (PQ/BA) como preditor não-invasivo de varizes esofágicas em cirróticos. Métodos - Este estudo transversal avaliou cirróticos quanto ao $\mathrm{PQ} / \mathrm{BA}$ e à presença de varizes esofágicas. Prontuários ambulatoriais de cirróticos foram revisados quanto a tais dados. Sensibilidade, especificidade e valores preditivos negativo e positivo do PQ/BA foram calculados. Após a análise univariada, variáveis com $P<0,10$ foram submetidas à regressão logística. Resultados - $\mathrm{O}$ estudo incluiu 164 cirróticos, $59,70 \%$ masculinos, com média de idade de 56,7 anos. Hepatite $\mathrm{C}$ foi a mais frequente causa de cirrose, estando presente em 90 pacientes. Os pacientes foram classificados como Child-Pugh A em 52,44\% e em Child-Pugh B ou C em 47,56\%. As varizes esofágicas estiveram presentes à endoscopia em 72,56\% dos pacientes. $\mathrm{PQ} / \mathrm{BA}$, com um ponto de corte de $3 \times 10^{8}$, teve sensibilidade de $95,80 \%$ (intervalo de confiança de $95 \%$ - IC $95 \%=0,92-0,99$ ), especificidade de $22,70 \%$ (IC95\%=0,10-0,35), valor preditivo positivo de 77,20\% (IC95\%=0,70-0,84) e valor preditivo negativo de 66,70\% (IC95\%=0,42-0,91). Na regressão logística, apenas a contagem de plaquetas e o escore de Child-Pugh associaram-se às varizes esofágicas $(P<0,05)$. Conclusão - PQ/BA apresentou excelente sensibilidade para predizer varizes esofágicas, permitido que cerca de um quarto dos pacientes sem varizes esofágicas evitasse a endoscopia. Entretanto, $\mathrm{PQ} / \mathrm{BA}$ não se associou de maneira independente às varizes esofágicas.

DESCRITORES - Cirrose hepática. Varizes esofágicas e gástricas. Hipertensão portal. Endoscopia gastrointestinal. Contagem de plaquetas.

\section{REFERENCES}

1. Abraldes JG, Bureau C, Stefanescu H, Augustin S, Ney M, Blasco H, et al Noninvasive tools and risk of clinically significant portal hypertension and varices in compensated cirrhosis: The "Anticipate" study. Hepatology. 2016;64: 2173-84.

2. Bosch J, Berzigotti A, Garcia-Pagan JC, Abraldes JG. The management of portal hypertension: rational basis, available treatments and future options. $\mathrm{J}$ Hepatol 2008;48:S68-92.

3. Chawla S, Katz A, Attar BM, Gupta A, Sandhu DS, Agarwal R. Platelet count/ spleen diameter ratio to predict the presence of esophageal varices in patients with cirrhosis: a systematic review. Eur J Gastroenterol Hepatol. 2012;24: 431-6.

4. Colecchia A, Montrone L, Scaioli E, et al. Measurement of spleen stiffness to evaluate portal hypertension and the presence of esophageal varices in patients with HCV-related cirrhosis. Gastroenterology. 2012;143:646-54.

5. De Franchis R, Baveno VI Faculty. Expanding consensus in portal hypertension: Report of the Baveno VI Consensus Workshop: Stratifying risk and individualizing care for portal hypertension. J Hepatol. 2015;63:743-52.

6. European Association for the Study of the Liver, Asociación Latinoamericana para el Estudio del Hígado. EASL-ALEH Clinical Practice Guidelines: Non-invasive tests for evaluation of liver disease severity and prognosis. $\mathbf{J}$ Hepatol. 2015; 63: 237-64
7. Garcia-Tsao G, Sanyal AJ, Grace ND, Carey W, Practice Guidelines Committe of the American Association for the Study of Liver Diseases, Practice Parameters Committee of the American College of Gastroenterology. Prevention and management of gastroesophageal varices and variceal hemorrhage in cirrhosis. Hepatology. 2007;46:922-38.

8. Mattos AZ, Mattos AA, Vianna FF, Musskopf MI, Pereira-Lima JC, Maciel AC Platelet count/spleen diameter ratio: analysis of its capacity as a predictor of the existence of esophageal varices. Arq Gastroenterol. 2010; 47:275-8.

9. Mattos AZ, Mattos AA. Noninvasive methods for esophageal varices prediction in cirrhotic patients: are we there yet? [Letter] Gastroenterology. 2013;144:1151-2.

10. Wai CT, Greenson JK, Fontana RJ, et al. A simple noninvasive index can predict both significant fibrosis and cirrhosis in patients with chronic hepatitis C. Hepatology. 2003:38:518-26.

11. Wang JH, Chuah SK, Lu SN, et al. Transient elastography and simple blood markers in the diagnosis of esophageal varices for compensated patients with hepatitis B virus-related cirrhosis. J Gastroenterol Hepatol. 2012;27:1213-8.

12. Ying L, Lin X, Xie ZL, Hu YP, Shi KQ. Performance of platelet count/spleen diameter ratio for diagnosis of esophageal varices in cirrhosis: a meta-analysis. Dig Dis Sci 2012;57:1672-81.

13. Zambam de Mattos A, Alves de Mattos A, Daros LF, Musskopf MI. Aspartate aminotransferase-to-platelet ratio index (APRI) for the non-invasive prediction of esophageal varices. Ann Hepatol. 2013;12:810-4. 